\title{
VOLATILITY TRANSMISSION BETWEEN MONEY AND STOCK MARKETS: EVIDENCE FROM A DEVELOPING FINANCIAL MARKET
}

\author{
Kalu 0 Emenike \\ Rhema University \\ emenikekaluonwukwe@yahoo.com
}

Received: March 2015

Accepted: September 2015

\begin{abstract}
The direction and intensity of volatility transmission between the money and stock markets are important for portfolio selection and diversification, optimal hedging strategy, financial market regulation, and risk management. The purpose of this paper therefore is to examine the nature of volatility transmission between money and stock markets in a developing economy using Nigeria data. The results of the bivariate BEKK-GARCH $(1,1)$ model show strong evidence of ARCH and GARCH effects for both the money and stock markets returns. The results also suggest unidirectional shock transmission from the stock market to the money but not otherwise. Further, the results indicate evidence of a unidirectional volatility transmission from the stock market to the money market. The findings of this study have implications for portfolio selection and diversification as well as financial market regulation.
\end{abstract}

Keywords

Money market, stock market, volatility transmission, GARCH model, developing financial market

Dr KO Emenike is a lecturer in the Department of Banking and Finance, Rhema University, Nigeria. 


\section{INTRODUCTION}

The active sources of financing available in most developing economies are money and capital markets. The basis of the distinction between the money market and capital market lies in the degree of tenor of the instruments traded in each of these markets. While the capital market is basically for long-term financing, the money market creates an avenue for investment in shortterm funds. These markets are however linked in terms of serving as veritable sources of investments in financial assets, avenues for assets or portfolio diversification and means of implementing hedging strategies. During the period of the global financial crisis, many investors reduced their exposures in the stock markets and increased their investments in the money markets. In Nigeria, for example, industry asset allocation of pension fund administrators show a reduction of equities investments from $20.07 \%$ in 2008 to $14.43 \%$ in 2009 , and at same time increased investments in money market assets from $30.25 \%$ in 2008 to $35.45 \%$ in 2009. Again, advances in communication and information technology (ICT) have contributed in no small measure to money and stock market linkages. Improved ICT, especially internet-based technologies, has increased the speed of dissemination of news across the globe as well as given investors access to the most recent news and information on their portfolio of investments. Also, computerised trading and settlement systems have facilitated the process of investors' exit from one market and entry into another through the internet. These few examples show the extent of linkage between the money and stock markets as alternative investment avenues, and suggest the existence of shock and volatility transmission among the markets.

Close examination of the nature of volatility transmission, according to Hurditt (2004), is important in aiding the effectiveness of monetary policy and in addressing financial stability issues. With regard to monetary policy, it is critical to understand the manner in which shocks are propagated across markets in order to determine the persistence of these innovations and the magnitude of their effects over time. The extent to which volatility is transmitted across markets could result in a large shock in one market destabilising another market. The ability of financial market regulators to gauge the depth and duration of the impact of cross-market and common market shocks could aid the implementation of timely and effective monetary policy. Regarding financial stability, it is extremely important to understand the various market price interrelationships. The complexity of these interrelationships represents a potential source of systemic financial instability. Hence, the need to understand the complex money and stock markets returns volatility interrelationships.

Numerous empirical studies have examined volatility transmission between financial markets across geographic boundaries, within domestic financial markets, between sectors of markets and across asset types (see for example, Engle et al., 1990; Hamao et al., 1990; Hong, 2001; Steeley, 2006; Arouri et al., 2011). One of the reasons for conducting these studies is the advent of international financial markets integration resulting from globalisation and advancement in ICT. While many earlier studies concentrated on international volatility linkages across developed countries, very few studies have examined stock and money markets volatility transmission, despite the crucial importance of dynamic volatility interactions between money and stock markets for diversification of asset classes, implementing hedging strategy and risk management. The few studies that examine volatility linkages between stock and money markets include Badrinath and Apte (2005), Fleming et al. (1998), and Turkyilmaz and Balibey, (2013). While these studies were conducted using developed and emerging market data, there is no such study in the case of Nigeria. 
This paper therefore intends to close this research lacuna in Nigeria by providing an answer to the question: what is the nature of volatility transmission between money and stock markets? The answer to this question is important to investors and regulators, because the extent to which volatility is transmitted across these markets could result in a large shock in one market destabilising another market. As a result, evidence of volatility transmission between these financial markets is not only useful in building accurate hedging strategies and forecasts of the volatility for both markets but could also aid in devising effective proactive policy measures to guide against systemic risk or market-specific instability that may arise from shock or volatility of any of the markets. In addition, this paper will contribute to the literature particularly on volatility transmission between money and stock markets of developing countries and point the way for further enquiry into the subject for future studies. Section 2 briefly reviews the empirical literature. Section 3 describes the sources of data and methodology. Section 4 contains empirical results, and section 5 concludes.

\section{BRIEF REVIEW OF EMPIRICAL LITERATURE}

The early empirical studies of return and volatility transmission concentrated on cross-country interdependence between different assets or markets. Hamao et al. (1990), for example, analyse the short-run interdependence of prices and price volatility across London, New York and Tokyo stock markets in the pre-October period. They show evidence of price volatility spillover from New York to London, from New York to Tokyo and from London to Tokyo but not in other directions. Other empirical studies that find evidence of cross-country volatility spillover include Hong (2001), Bhar and Hamori, (2003), and Inagaki (2007).

While substantial literature exists on volatility transmission between stock and bond markets, the literature on the transmission of volatility between stock market and money market is scanty. The bond market overlaps both the money and stock market. Gilt-edged securities maturing within one year are money market instruments. Examples of such instruments include 90 and 180 days treasury bills. But beyond one year, they become capital market instruments. The proxy for the money market has varied across studies. While, for instance, Fleming et al. (1998) used the Chicago Mercantile Exchange Treasury bill futures contract as the proxy for the money market, Badrinath and Apte (2005) used the call money rate.

Dean et al. (2010) investigate asymmetry in return and volatility spillover between equity and bond markets in Australia during the period 1992-2006 using a bivariate GARCH modelling approach. They provide evidence to show that negative bond market returns spill over into lower stock market returns, whereas good news originating in the equity market leads to lower bond returns. They also find unidirectional volatility transmission from bond to equity markets. Zhang et al. (2013) examine volatility spillovers between equity and bond markets in G7 and BRICS countries. Their results show that there is bidirectional volatility spillovers between the equity and bond markets in France, Brazil and South Africa, and unidirectional spillovers from the bond to the equity in the US, UK and Germany. Other earlier studies on equity and bond markets volatility transmission include Fang et al. (2006), Fang et al. (2007), and Chuliá and Torró (2007).

The little literature that there is on volatility transmission between money and stock markets, however, suggests that volatility transmission exists between the markets, although a consensus on the direction has yet to be reached. Fleming et al. (1998) investigate the nature of information and volatility linkages in the stock, bond, and money markets. They find that, among other things, volatility linkages between the markets are indeed strong and that the linkages have become 
stronger since the 1987 stock market crash. They attributed their finding to a shift in volatility regimes and an increase in cross-market hedging due to greater futures market liquidity in the post-crash period. They conclude that strong volatility linkages are a key feature of the stock, bond, and money markets. Badrinath and Apte (2005) examine the stock market, foreign exchange and call money markets in India for evidence of volatility spillovers using multivariate EGARCH models, which facilitate the study of asymmetric responses of the conditional variance of asset returns to both positive and negative innovations in the return generating process. Their results indicate, among other things, the existence of symmetric volatility spillovers from the call money market to the stock market and asymmetric volatility spillovers from the stock market to the call money market. Similarly, Turkyilmaz and Balibey (2013) find evidence of significant transmission of shocks and volatility between interest rate, exchange rate and stock price in Turkey using the GARCH-BEKK approach.

\section{SOURCES OF DATA AND METHODOLOGY}

\subsection{Methodology}

Multivariate GARCH models have been designed to model the conditional covariance matrix of multiple time series. The BEKK parameterisation of the bivariate GARCH model following Engle and Kroner (1995) is adopted to investigate the nature volatility transmission between money and stock markets in Nigeria. In this model, the variance covariance matrix equations depends on the squares and cross-products of $\varepsilon_{t}$, which is derived from the following mean equation:

$$
R_{t}=\mu_{i}+\theta R_{i, t-1}+\varepsilon_{t}, \quad \varepsilon_{t}=H_{t}^{1 / 2} \eta_{t}
$$

where $R_{t}=\left(R_{t}^{M}, R_{t}^{S}\right)$ is a vector of returns of the money and stock markets respectively, $\theta$ refers to a $2 \times 2$ matrix of coefficients, and $\varepsilon_{t}=\left(\varepsilon_{t}^{M}, \varepsilon_{t}^{S}\right)$ is the vector of error terms of conditional mean equation for money and stock markets returns respectively. $\eta_{t}=\left(\eta_{t}^{M}, \eta_{t}^{S}\right)$ is a sequence of independently and identically distributed (i.i.d) random errors; $h_{t}=\left(\begin{array}{cc}h_{t}^{M} & h_{t}^{M S} \\ . & h_{t}^{S}\end{array}\right)$ is the conditional variance-covariance of money and stock markets returns.

The standard BEદK parameterisation for the bivariate GARCH model is specified thus:

$$
H_{t}=C C^{\prime}+A \varepsilon_{t-1} \epsilon_{t-1}^{\prime} A^{`}+B H_{t-1} B^{`}
$$

where $H t$ is the BEKK conditional variance matrix, $C$ is a $2 \times 2$ lower triangular matrix that corresponds to the constant, $A$ is a $2 \times 2$ matrix of ARCH parameters and $B$ is a $2 \times 2$ matrix of GARCH parameters. In this parsimonious specification the conditional variances are a function of the lagged conditional variances and error terms. To identify more clearly how the money and stock markets volatilities interact, consider the matrix multiplication of the bivariate GARCH-BEKK specification from equation (2): 


$$
\begin{aligned}
{\left[\begin{array}{ll}
h_{M M, t} h_{M S, t} \\
h_{S M, t} h_{S S, t}
\end{array}\right]=} & {\left[\begin{array}{cc}
c_{M M}^{0} & c_{M S}^{0} \\
0 & c_{S S}^{0}
\end{array}\right]^{\prime}\left[\begin{array}{cc}
c_{M M}^{0} & c_{M S}^{0} \\
0 & c_{S S}^{0}
\end{array}\right]+} \\
& {\left[\begin{array}{cc}
a_{M M}^{*} & a_{M S}^{*} \\
a_{S M}^{*} & a_{S S}^{*}
\end{array}\right]^{\prime}\left[\begin{array}{cc}
\varepsilon_{M}^{2},_{t-1} & \varepsilon_{M},_{t-1} \varepsilon_{S},_{t-1} \\
\varepsilon_{M},_{t-1} \varepsilon_{S},_{t-1} & \varepsilon_{S}^{2},_{t-1}
\end{array}\right]\left[\begin{array}{ll}
a_{M M}^{*} & a_{M S}^{*} \\
a_{S M}^{*} & a_{S S}^{*}
\end{array}\right]+} \\
& {\left[\begin{array}{ll}
b_{M M}^{*} & b_{M S}^{*} \\
b_{S M}^{*} & b_{S S}^{*}
\end{array}\right]^{\prime}\left[\begin{array}{ll}
h_{M M, t-1} & h_{M S, t-1} \\
h_{S M, t-1} & h_{S S, t-1}
\end{array}\right]\left[\begin{array}{ll}
b_{M M}^{*} & b_{M S}^{*} \\
b_{S M}^{*} & b_{S S}^{*}
\end{array}\right] }
\end{aligned}
$$

where $h_{M M, t}$ denotes the conditional variance of money market rate of return, $h_{M S, t}$ the covariance of money market rate returns and stock market returns, and $h_{S S, t}$ the conditional variance of stock market returns. The significance of the diagonal coefficients $a_{M M, t}\left(a_{M M, t}\right)$ suggests that the current conditional variance of $h_{M M, t}\left(h_{M S, t}\right)$ is correlated with its own past squared errors, while the significance of the lagged variance $b_{M M, t}\left(b_{S S, t}\right)$ indicates that the current conditional variance of $h_{M M, t}\left(h_{M S, t}\right)$ is affected by its own past conditional variance. In the same vein, the significance of the off-diagonal coefficients $a_{M S, t}$ and $b_{M S, t}$ indicates evidence of shock and volatility transmission from the money market to the stock market, whereas the significance of the off-diagonal coefficients $a_{S M, t}$ and $b_{S M, t}$ shows evidence of shock and volatility transmission from the stock market to the money market.

The matrix multiplication leads to equations (4) and (5), where $h_{M, t}^{2}$ and $h_{S, t}^{2}$ are conditional volatilities of the money market and stock market respectively, $h_{M S, t}^{2}$ is the conditional covariance, $\varepsilon_{M, t}^{2}, \varepsilon_{S, t}^{2}$ and $\varepsilon_{M, t} \varepsilon_{S, t}$ are the lagged own squared and cross-market random shocks.

$$
\begin{aligned}
& h_{M M, t+1}=c_{M M}^{2}+a_{M M}^{2} \varepsilon_{M, t}^{2}+2 a_{M M} a_{M S} \varepsilon_{M, t} \varepsilon_{S, t}+a_{S M}^{2} \varepsilon_{S, t}^{2}+b_{M M}^{2} h_{M M, t}^{2}+2 b_{M M} b_{M S} h_{M S, t}+b_{S M}^{2} h_{S S, t} \\
& h_{S S, t+1}=c_{M S}^{2}+c_{S S}^{2}+a_{M S}^{2} \varepsilon_{M, t}^{2}+2 a_{M S} a_{S S} \varepsilon_{M, t} \varepsilon_{S, t}+a_{S S}^{2} \varepsilon_{S, t}^{2}+b_{M S}^{2} h_{M M, t}^{2}+2 b_{M S} b_{S S} h_{M S, t}+b_{S S}^{2} h_{S S, t}
\end{aligned}
$$

Maximum likelihood estimates of the parameters in equations (4) and (5) were obtained using the Broyden, Fletcher, Goldfarb, and Shanno (BFGS) algorithm. The likelihood element for an $n-$ vector at time $t$ is

$$
L(\theta)=-\frac{1}{2} \log 2 \pi-\frac{1}{2} \log \left|\Sigma_{t}\right|-\frac{1}{2} \varepsilon_{t}^{\prime} \sum_{t}^{-1} \varepsilon_{t}
$$

where $\theta$ is the parameter vector to be estimated.

For a properly fitted model, the residuals and the standardised residuals should form a sequence of /ID random variable. This implies that the series should be uncorrelated and should not display any remaining conditional volatility (Enders, 2004: 136; Tsay, 2005: 44). The fitted multivariate model is examined for possible inadequacy using the Ljung-Box (1978) $Q$ statistic to test the null hypothesis of no serial correlation in estimated residuals and squared residuals up to a specific lag, and the Engle (1982) LM statistic was used to test the null hypothesis of ARCH effects up to a specific order. Evidence of nonlinear dependence in the estimated residuals and squared residuals would indicate misspecification in the multivariate GARCH model. 


\subsection{Sources of data}

Monthly observations on the interbank call rate and all-share index (ASI) of the Nigerian Stock Exchange (NSE) were obtained as proxies for the money market and stock market respectively, for the January 2003 to March 2013 period, totalling 123 observations for each series. The interbank market is a short-term money market, which allows large financial institutions such as banks, mutual funds and corporations to borrow and lend money at interbank call rates. The loans in the call money market are very short, usually lasting no longer than a week, and are often used to help banks meet reserve requirements.

The choice of interbank call rate as a proxy for the money market is due its role as the mechanism by which monetary policy is transmitted to the money market and the real economy. Olowe (2011) notes that the Interbank call rate reflects the supply and demand behaviour of bank reserves, and gives important signals to the Central Bank of Nigeria to understand the market pressure. It also has a close link with other interest rates in the financial market and the foreign exchange rate. The interbank rate series were collected from the Central Bank of Nigeria statistics databank and transformed to change in interbank call rate by taking their first difference. The ASI was obtained from the NSE and converted into monthly returns as the first log difference. Thus:

$$
R_{t}=\operatorname{Ln}\left(\frac{P_{t}}{P_{t-1}}\right) \times 100
$$

where $R_{t}$ is the daily returns, $P_{t}$ is closing ASI for Month $t, P_{t-1}$ is the previous month's closing ASI, and $L n$ is the natural logarithm.

\section{EMPIRICAL RESULTS}

\subsection{Descriptive statistics}

FIGURE 1 contains time series plots of the levels and returns series of the money and stock markets. Notice from FIGURE 1 that the stock market exhibits a strong upward trend, which peaked in the first quarter of 2008, before moving southward, as a result of the global financial crisis, before moving upward again from November 2010. The return series, on the other hand, show two major spikes. The first represents the period of the global financial crisis and the second depicts the massive sell-offs sparked by the sovereign debt crisis in Europe and USA in 2011, which affected the global financial markets. On 26 0ctober 2011 , for example, the Nigeria stock market was down by $18.1 \%$ to $20,278.16$, having opened the year at $24,770.52$.

Summary statistics for the return series in each market are displayed in TABLE 1 . The average return in stock market over the sample period was positive and represents an annualised rate of about $9.07 \%$, with a standard deviation of $9.69 \%$, whereas the mean change in interbank call rate is negative, with a very high standard deviation. The distribution of the stock market returns and the interbank call rate series are leptokurtic and negatively skewed. The Jarque-Bera statistics suggest that the null hypothesis of normality would be rejected for the two series.

In both series there is evidence of significant autocorrelation, as shown by the Ljung-Box $\rho$ (from Ljung and Box, 1978). This provides support for the estimation of the autoregressive mean equation. Similarly, the McLeod-Li (following McLeod-Li, 1983) and ARCH-LM estimates reject the null hypothesis of no autocorrelation in the squared residual, thus providing support for heteroscedasticity in the series. 


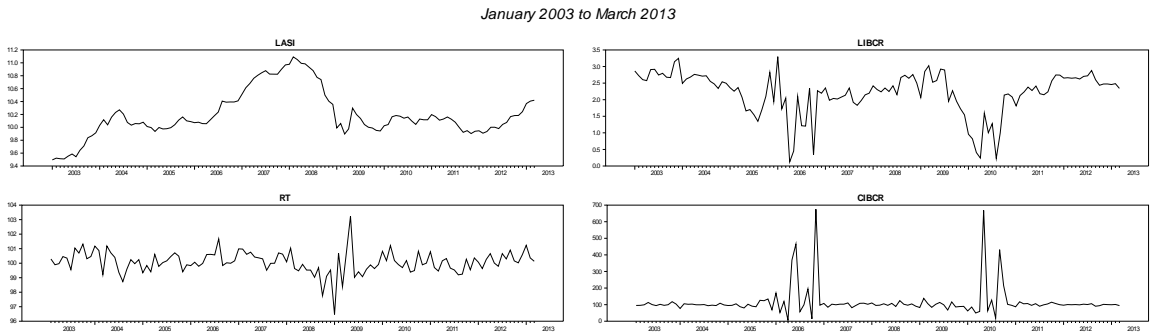

FIGURE 1: Time plot of NSE Returns vs. Change in interbank call rate

Source: Author's calculations

TABLE 1: Descriptive Statistics and Test for ARCH \&ffect

\begin{tabular}{lllllllll}
\hline & Mean & S.D & Skew. & E.Kurt & JBStat & LM(12) & McL(22) & $\rho(22)$ \\
\hline Rt & 0.758 & 7.820 & -0.584 & 5.699 & 172.07 & 31.27 & 35.74 & 41.10 \\
CIBCR & -0.431 & 52.806 & -0.111 & 5.094 & 132.20 & 30.55 & 96.61 & 51.02 \\
\hline
\end{tabular}

Source: Author's analysis

Note: The ARCH LM tests are conducted under the null hypothesis of no ARCH effect and at a $99 \%$ confidence level using squared returns. The Ljung-Box statistic, $\rho(12)$, checks for the serial correlation of the returns up to the 22 order, while the McLeod-Li (22) estimate checks for the serial correlation of the squared returns up to the 22 order.

\subsection{Unit Root Tests Results}

TABLE 2 contains the results of the Dickey-Fuller unit root tests (from Dickey and Fuller, 1979) and KPSS (Kwaitkowski et al., 1992) stationarity tests for the level series and their returns. The null hypothesis of the ADF test is that a time series contains a unit root, whereas the null hypothesis of the KPSS test is that a time series is stationary. As shown in TABLE 2, the calculated values of the ADF test statistics indicate that the level series contain a unit root at the $1 \%$ significance level, implying that the level series are non-stationary.

\section{TABLE 2: Unit Root and Stationarity Tests Results}

\begin{tabular}{lllllllll}
\hline & \multicolumn{3}{c}{ ADF } & & \multicolumn{5}{c}{ KPSS } \\
\hline & Level & & l. diff & & Level & \multicolumn{3}{c}{1 d diff } \\
Variables: & $5 \%$ & computed & $5 \%$ & computed & $5 \%$ & computed & $5 \%$ & computed \\
Rt & -3.447 & -2.496 & -3.44 & $-4.844 \star \star$ & 0.146 & $0.396 * \star$ & 0.146 & 0.111 \\
IBCR & -3.446 & -3.236 & -3.44 & $-10.523 * \star$ & 0.146 & $0.187 *$ & 0.146 & 0.0315 \\
\hline
\end{tabular}

Source: Author's analysis

Note: ADF and KPSS lag lengths are selected using the Akaike information criterion (AIC). ** indicates significance at the $99 \%$ confidence level. 
However, in the case of the return series, the statistics reject the null hypothesis of a unit root at the $1 \%$ significance level, implying that the returns are stationary for the two series. The results of the KPSS tests, on the other hand, show that the level series are non-stationary, whereas their first differences are stationary.

\subsection{Covariance Matrix Estimates}

TABLE 3 displays the covariance matrix between squared money market and stock market returns series. The covariance matrix is a measure of the extent to which two variables tend to move together. Casual inspection of TABLE 3 shows that the covariance of money market return with itself is very high, but the covariance of money market return with stock market return is zero. $0 \mathrm{n}$ the other hand, it can be noted that the covariance of stock market return with money market return is higher than the covariance with itself. This suggests that the variance of both money markets may be unrelated with that of the stock market.

TABLE 3: Money and Stock Markets Returns Covariance Matrix

\begin{tabular}{lcc}
\hline & $\Delta M M R^{2}$ & $S M R^{2}$ \\
\hline$\triangle M M R^{2}$ & 59997458.89 & 0.05802 \\
$S^{2} R^{2}$ & 78316.91 & 30363.59 \\
\hline
\end{tabular}

Source: Author's analysis

Note: MMR' is squared money market returns, and SMR' is the stock market return squared.

\subsection{Multivariate GARCH-BEKK Results}

TABLE 4 contains the estimates from the bivariate GARCH (1.1)-BEKK model employed to investigate the nature of volatility transmission between the money and stock markets. The empirical results show that the diagonal parameters $A_{M M}, A_{S S}, B_{M M}$ and $B_{S S}$ are all statistically significant at the $99 \%$ confidence level. This indicates that a strong ARCH and GARCH (1.1) process drives the conditional variances of the money and stock markets returns. In other words, own past shock and volatility directly affect returns in the money and stock markets in Nigeria.

The off-diagonal elements of matrices $A$ and $B$ capture cross-market shock and volatility transmission between the money and stock markets. From the off-diagonal elements of matrix $A$, we see evidence of unidirectional negative shock transmissions from the stock market to the money market $\left(A_{(S, M)}\right)$ at the $10 \%$ significance level. With $90 \%$ confidence, this result suggests that negative shock from the stock market transmits into negative money market shock. In contrast, shock in the money market does not affect the stock market. Evidence of unidirectional shock transmission from the stock market to the money market is not surprising given that banking companies in Nigeria, which are major players in the money market, dominate the Nigerian stock markets. For example, SEC (2010) reports that about 4.04 billion banking sector shares valued at \#32.87 billion were exchanged in 70,307 deals, representing $51.35 \%, 60.80 \%$ and $52.81 \%$ of the month's total volume, value and number of deals respectively, on the Nigerian Stock Exchange. SEC (2013) provides a similar report. Given this dominance of the stock market by the money market players, it is not surprising that negative stock market information reflects in the money market. 
The results of the off-diagonal elements of matrix $B$ also indicate evidence of unidirectional volatility transmission from the stock market to the money market. This is evident in the significance of the off-diagonal parameter $B_{S M}$ at the $99 \%$ confidence level. The results suggest a strong volatility transmission from stock market to money market but not the reverse. These results partly agree with the literature. Badrinath and Apte (2005), for instance, find evidence of bidirectional symmetric volatility linkages from call money to stock market and asymmetric volatility spillover from stock market to call money market. These results have implications for investors and policymakers. Since these markets are partially integrated, money market investors can reduce risk in the long run by holding assets from the stock market in the same portfolio. In addition, investors can hedge their position in the money market using the stock market, since shock and volatility from the money market do not transmit to the stock market. Policymakers, for their part, have to take serious account of the developments in the stock market, as a shock in the stock market may have a destabilising affect on the money market. Again, there should be handy cushion policies based on stress tests and scenario analysis to absorb any unexpected impacts of negative shocks from the stock market to the money market.

Panel B of TABLE 3 contains the results of diagnostic tests conducted to examine the adequacy of the fitted model. $\rho m(22), \rho m^{2}(22)$ and $\rho s$ (22), $\rho s^{2}(22)$ are the Ljung-Box $\rho$ tests on the levels and squared residuals series, with 22 lags, of the money and stock markets respectively. They are distributed with $\chi 2$ (22) under the null of no autocorrelation. MV $\rho$ and $M V L M$ are multivariate Ljung-Box test and multivariate Lagrange multiplier for the existence of ARCH effects. Notice from Panel $B$ that the $Q$-statistics for both the residuals series and squared residuals series of money and stock markets are insignificant, suggesting that there are no autocorrelations in their residuals and squared residuals. Similarly, the multivariate ARCH-LM and Ljung-Box results show evidence in support of the null hypotheses of no remaining ARCH effects and no serial correlation at the $99 \%$ confidence level. Hence, the model is adequate to explain volatility linkages between the money and stock markets.

TABLE 4: Estimated Results of the GARCH-BEKK Model

\begin{tabular}{lccc}
\hline Parameters & Coefficients & t-statistic & P-value \\
\hline$C_{(\mathrm{M}, \mathrm{M})}$ & 0.0677 & 3.1560 & 0.0015 \\
$\mathrm{C}_{(\mathrm{s}, \mathrm{M})}$ & -0.0271 & -3.9858 & 0.0000 \\
$\mathrm{C}_{(\mathrm{s}, \mathrm{S})}$ & 0.0000001 & $3.84577 \mathrm{e}-006$ & 0.9999 \\
$\mathrm{~A}_{(\mathrm{M}, \mathrm{M})}$ & 1.0798 & 7.0716 & 0.0000 \\
$\mathrm{~A}_{(\mathrm{M}, \mathrm{S})}$ & -0.0017 & -0.1081 & 0.9139 \\
$\mathrm{~A}_{(\mathrm{S}, \mathrm{M})}$ & -0.5497 & -1.8471 & 0.0647 \\
$\mathrm{~A}_{(\mathrm{S}, \mathrm{S})}$ & 0.3498 & 4.5796 & 0.0000 \\
$\mathrm{~B}_{(\mathrm{M}, \mathrm{M})}$ & 0.5105 & 6.8426 & 0.0000 \\
$\mathrm{~B}_{(\mathrm{M}, \mathrm{S})}$ & -0.0010 & -0.0949 & 0.9243 \\
$\mathrm{~B}_{(\mathrm{s}, \mathrm{M})}$ & 0.8440 & 4.2631 & 0.0000 \\
$\mathrm{~B}_{(\mathrm{s}, \mathrm{S})}$ & 0.8658 & 17.8904 & 0.0000 \\
& Panel B: Diagnostic Tests Results & \\
\hline
\end{tabular}




\begin{tabular}{|c|c|c|}
\hline & Statistic & $p$-value \\
\hline$Q_{\text {M }}(22)$ & 21.519 & 0.488 \\
\hline $\mathrm{Qm}^{2}(22)$ & 26.439 & 0.233 \\
\hline$Q_{s}(22)$ & 27.880 & 0.179 \\
\hline$\rho_{s}^{2}(22)$ & 24.585 & 0.317 \\
\hline MV LM $\{22\}$ & 19.71 & 0.601 \\
\hline MV P (22) & 23.362 & 0.381 \\
\hline
\end{tabular}

Source: Author's analysis

Note: $\rho \mathrm{m}$ and $\rho$ s are the Ljung-Box $\rho$-statistics for the money market and stock market respectively. MV LM and $\rho$ are multivariate ARCH-LM and Ljung-Box $Q$-statistic for null hypotheses of no ARCH effects and no autocorrelation in the multivariate GARCH model. Lag length is displayed as (.). All the tests are conducted at $5 \%$ significant levels.

\section{CONCLUSIONS}

Volatility transmission between the money market and stock market are of particular interest to academics, investors (institutional and individual), and financial market regulators due to the importance of the markets to the economy. As a result, this paper aims at answering the question: what is the nature of volatility transmission between the money market and stock market in a developing economy using Nigeria data. The results of the bivariate GARCH (1.1)-BEKK model indicate that own past shock and volatility affect the current returns in the money market and stock market in Nigeria. The results also show weak unidirectional shock transmission from the stock market to the money market without a corresponding flow from the money market to the stock market. The results further show evidence of unidirectional shock transmission from the stock market to the money market, but not otherwise. The findings, generally, provide support for unidirectional shock and volatility transmission from the stock market to the money market in Nigeria. The investment implication is for risk management and diversification by money market investors using the stock market in the same portfolio, and the policy usefulness is for policymakers to make handy cushion policies based on stress tests and scenario analysis to absorb any unexpected impacts of shock and volatility from the stock market to the money market.

\section{LIST OF REFERENCES}

Arouri, M. E. H., Jouini, J., \& Nguyen, D. K. (2011). Volatility spillovers between oil prices and stock sector returns: Implications for portfolio management. Journal of International Money and Finance, 30(7), pp. 1387-1405.

Badrinath, H.R. \& Prakash G. Apte (2005). Volatility spillovers across stock, call money and foreign exchange markets. Department of Economics (San Diego, University of California).

Bhar, R. \& Hamori, S. (2003). New evidence of linkages among G-7 stock markets. Finance Letters, 1, pp. $35-40$. 
Chuliá, H. \& Torró, H. (2007). The economic value of volatility transmission between the stock and bond markets. Available: http://ssrn.com/abstract $=938150$.

Dean, W. G.; Faff, R. W. \& Loudon, G. F. (2010). Asymmetry in return and volatility spillover between equity and bond markets in Australia. Pacific-Basin Finance Journal, 18(3), pp. 272-289.

Dickey, D. A. \& Fuller, W. A. (1979). Distribution of estimators for time series regressions with a unit root. Journal of American Statistical Association, 74, pp. 427-431.

Enders, W. (2004). Applied econometric time series, $2^{\text {nd }}$ edition. Singapore: John Wiley \& Sons.

Engle, R.F. (1982). Autoregressive conditional heteroscedasticity with estimates of the variance of the United Kingdom inflation. Econometrica, 50, pp. 987-1008.

Engle, R.F., Ito, T. \& Lin, W.L. (1990). Meteor showers or heat waves? Heteroskedastic intra-daily volatility in the foreign exchange market, Econometrica, 58(3), pp. 525-542.

Engle, R.F. \& Kroner, K.F. (1995). Multivariate simultaneous generalized ARCH. Econometric Theory, 11, pp. 122-150.

Fang, V., Lim, Y. \& Lin, C.T. (2006).Volatility transmissions between stock and bond markets: Evidence from Japan and the U.S. International Journal of Information Technology, 12 (6), pp. 120-128.

Fang, V., Lin C.T., \& Lee, V. (2007). Volatility linkages and spillover in stock and bond markets: Some international evidence. Journal of International Finance and Economics, 7(1), pp. 1-10.

Fleming, J.; Kirby, C. \& Ostdiek, B. (1998). Information and volatility linkages in the stock, bond and money markets. Journal of Financial Economics, 49, pp. 111-137.

Hamao, Y., Masulis, R.W. \& Ng, V. (1990). Correlations in price changes and Volatility across International Stock Markets. Review of Financial Studies, 3 (2), 281-307.

Hurditt, P. (2004). An assessment of volatility transmission in the Jamaican financial System. Journal of Business, Finance and Economics in Emerging Economies, 1(1), pp. 1-28.

Hong, Y. (2001). A test for volatility spillover with application to exchange rates. Journal of Econometrics, 103, pp. 183-224.

Inagaki, K. (2007). Testing for volatility spillover between the British pound and the euro. Research in International Business and Finance, 21, pp. 161-174.

Ljung, G.M., \& Box, G.E.P. (1978). On a measure of lack of fit in time series models. Biometrika, 67, pp. 279-303.

Kwaitkowski, D., Phillips, P., Schmidt, P. \& Shin, Y. (1992). Testing the null hypothesis of stationarity against the alternative of a unit root: How sure are we that economic time series have a unit root? Journal of Econometrics, 54, pp. 159-178.

McLeod, A., \& Li, W. (1983). Diagnostic checking ARMA time series models using squared residual autocorrelations. Journal of Time Series Analysis, 55, pp. 703-708.

Olowe, R. A. (2011). Inter-bank call rate volatility and the global financial crisis: The Nigerian case. International Journal of Economics and Finance, 3(1), pp. 283-296.

Securities and Exchange Commission (2010, February). Capital market bulletin, Abuja: SEC Printer.

Securities and Exchange Commission (2013, January). Capital market bulletin, Abuja: SEC Printer.

Steeley, J. M. (2006). Volatility transmission between stock and bond markets. Journal of International Financial Markets, Institutions, and Money, 16(1), pp. 71-86. 
Tsay, R. S. (2005). Analysis of financial time series, $2^{\text {nd }}$ edition. Hoboken, New Jersey: John Wiley \& Sons Inc.

Turkyilmaz, S. \& Balibey, M. (2013). The relationship among interest rate, exchange rate and stock prices: A BEKK-MGARCH approach. International Journal of Economics, Finance and Management Sciences, 1(3), pp. 166-174.

Zhang, J.; Zhang, D., Wang, J. and Zhang, Y. (2013). Volatility spillovers between equity and bond markets: Evidence from G7 and BRICS. Romanian Journal for Economic Forecasting, 4, pp. 205-217. 